\title{
Isolated Aerobic Exercise and Weight Loss: A Systematic Review and Meta-Analysis of Randomized Controlled Trials
}

\author{
Adrian Thorogood, BSc, ${ }^{a, b}$ Salvatore Mottillo, BSc, ${ }^{a, b, c}$ Avi Shimony, MD, ${ }^{a, b}$ Kristian B. Filion, PhD, ${ }^{d}$ \\ Lawrence Joseph, PhD, ${ }^{e, f}$ Jacques Genest, MD, ${ }^{g}$ Louise Pilote, MD, MPH, PhD, ${ }^{\text {e,f }}{ }^{\text {, }}$ Paul Poirier, MD, PhD, ${ }^{i}$ \\ Ernesto L. Schiffrin, MD, PhD, ${ }^{b, j}$ and Mark J. Eisenberg, MD, MPH ${ }^{a, b, e}$ \\ ${ }^{a}$ Divisions of Cardiology and Clinical Epidemiology, Jewish General Hospital/McGill University, Montreal, Quebec, Canada; ${ }^{b}$ Lady Davis Institute \\ for Medical Research, Jewish General Hospital, Montreal, Quebec, Canada; ${ }^{c}$ Faculty of Medicine, University of Montreal, Montreal, Quebec, \\ Canada; ${ }^{d}$ Division of Epidemiology and Community Health, School of Public Health, University of Minnesota, Minneapolis, Minn; ${ }^{e}$ Department of \\ Epidemiology, Biostatistics and Occupational Health, McGill University, Montreal, Quebec, Canada; ${ }^{f}$ Division of Clinical Epidemiology, ${ }^{g}$ Division of \\ Cardiology, and ${ }^{h}$ Division of Internal Medicine, McGill University Health Center, Montreal, Quebec, Canada; ${ }^{i}$ Faculty of Pharmacy, Laval Hospital, \\ Quebec Heart and Lung Institute, Quebec, Quebec, Canada, ${ }^{j}$ Department of Medicine, Jewish General Hospital, Montreal, Quebec, Canada.
}

\begin{abstract}
BACKGROUND: Aerobic exercise is a common nonpharmacological intervention for the management of obesity. However, the efficacy of isolated aerobic exercise at promoting weight loss is unclear. We conducted a systematic review and meta-analysis to evaluate the efficacy of isolated aerobic exercise programs in overweight and obese populations.

METHODS: We searched for published randomized controlled trial reports of aerobic exercise through January 20, 2010. Trials with an isolated aerobic exercise intervention were included. A random-effect model was used to synthesize the results of each intervention.

RESULTS: We identified 14 trials involving 1847 patients. The duration of aerobic exercise programs ranged from 12 weeks to 12 months. Results were pooled for programs with 6-month duration and programs with 12-month duration. Six-month programs were associated with a modest reduction in weight (weighted mean difference $[\mathrm{WMD}]=-1.6 \mathrm{~kg}$; 95\% confidence interval $[\mathrm{CI}],-1.64$ to -1.56 ) and waist circumference $(\mathrm{WMD}=-2.12 \mathrm{~cm} ; 95 \% \mathrm{CI},-2.81$ to -1.44$)$. Twelve-month programs also were associated with modest reductions in weight (WMD $=-1.7 \mathrm{~kg} ; 95 \% \mathrm{CI},-2.29$ to -1.11 ) and waist circumference (WMD $=-1.95 \mathrm{~cm} ; 95 \% \mathrm{CI},-3.62$ to -0.29$)$.

CONCLUSION: Moderate-intensity aerobic exercise programs of 6-12 months induce a modest reduction in weight and waist circumference in overweight and obese populations. Our results show that isolated aerobic exercise is not an effective weight loss therapy in these patients. Isolated aerobic exercise provides modest benefits to blood pressure and lipid levels and may still be an effective weight loss therapy in conjunction with diets. (C) 2011 Elsevier Inc. All rights reserved. • The American Journal of Medicine (2011) 124, 747-755
\end{abstract}

KEYWORDS: Abdominal obesity; Aerobic exercise; Cardiovascular risk; Meta-analysis; Obesity; Weight loss

In recent decades, the prevalence of adult obesity has increased substantially. In North America, 32.5\% of the population is overweight and $33.8 \%$ obese. ${ }^{1-3}$ Adult obesity

Funding: This work is supported by the Canadian Institutes of Health Research (CIHR grant number is 103506). Dr. Eisenberg is a ChercheurNational of the Fonds de la Recherche en Santé du Québec (FRSQ). Dr. Joseph is a Chercheur-National of the FRSQ. Dr. Pilote is a Chercheur-National of the FRSQ. Dr. Poirier is a Senior Physician-Scientist of the FRSQ. Dr. Schiffrin holds a Canada Research Chair in Vascular and Hypertension Research. poses many increased health risks including coronary artery disease, high blood pressure, dyslipidemia, type 2 diabetes, and stroke. Obesity contributes to an estimated 120,000 prevent-

Conflict of Interest: Dr. Genest is on the speaker's bureau for Merck and Astra Zeneca. No other authors have any conflicts of interest.

Authorship: All authors had access to the data and played a role in writing this manuscript.

Requests for reprints should be addressed to Mark J. Eisenberg, MD, MPH, Divisions of Cardiology and Clinical Epidemiology, Jewish General Hospital/McGill University, 3755 Rue Cote Ste. Catherine, Suite H-421, Montreal, QC H3T 1E2, Canada.

E-mail address: mark.eisenberg@mcgill.ca 
able deaths in North America each year. ${ }^{1,4}$ A lack of physical activity has contributed to this obesity epidemic as over $59 \%$ of North American adults are now considered inactive. ${ }^{1,3}$

Due to the link between obesity and physical inactivity, adults are recommended to engage in at least 150 minutes of moderate-intensity physical activity per week. ${ }^{1}$ Clinicians are encouraged to stress to their patients the importance of consistent exercise and daily physical activity. ${ }^{1}$ However, the efficacy of exercise and physical training to reduce obesity in patients has not yet been clearly demonstrated. In addition, exercise is perceived by many to be a costly, strenuous, and time-consuming endeavor. ${ }^{3}$ The benefits of aerobic exercise programs must be considered in light of these perceived barriers.

Although many trials assess aerobic exercise in combination with diet or pharmacotherapy, only a handful of studies examine the isolated effect of exercise (without caloric restriction) in overweight populations. Consequently, there is a need to systematically assess the efficacy of isolated aerobic exercise as a weight loss therapy. If isolated aerobic exercise is shown to be effective, its application will be encouraged in combination therapies. On the other hand, if isolated aerobic exercise is shown to have a minimal impact on weight loss, although this would not rule out synergistic effects of combination therapies, the focus of treatment could shift to other weight loss strategies.

We undertook a systematic review and meta-analysis of randomized controlled trials (RCTs) that evaluated the efficacy of isolated aerobic exercise on weight loss. The specific objective of this review was to determine the effect of isolated aerobic exercise on abdominal obesity, blood pressure, total cholesterol, triglyceride levels, and weight in overweight and obese populations.

\section{METHODS}

We carried out a literature search of the Cochrane Library and MEDLINE for all RCTs published in English or French between January 1, 1970 and January 20, 2010 (Appendix). Related systematic reviews were identified through Google Scholar. ${ }^{5-10}$ We reviewed RCTs cited in these reviews and in the bibliographies of included RCTs for additional reports not identified by database searching. The search strategy was designed to include all studies with an outcome term (weight, cardiovascular, or lipid measure), a term that would identify a population (morbid obesity, obesity, overweight), and an exercise term (exercise, exercise therapy, fitness, physical activity, physical exertion, physical train- ing, workout). We excluded RCTs containing the terms "neoplasm" and "cancer."

\section{Study Selection}

We included RCTs that compared an "exercise only" group (no concurrent caloric restriction or weight loss pharmacotherapy) to an inactive control group. Control groups were defined as inactive if patients were instructed not to change their current exercise habits and were not included in an exercise program. Medical attention and stretching control groups were accepted. We limited our systematic review to overweight (body mass index $[\mathrm{BMI}] \geq 25 \mathrm{~kg} /$ $\mathrm{m}^{2}$ ) adult ( $\geq 18$ years) populations. RCTs with a comorbidity or covariate generally unrelated to obesity (eg, cancer, pregnancy) were excluded. We included only RCTs with an exercise intervention longer than 12 weeks with at least 120 minutes per week. The intensity of the exercise (percent heart rate reserve, percent maximum oxygen consumption, and time exercised per week) also had to be reported. At least one measure of obesity (BMI, percent fat, waist hip ratio, waist circumference, or weight) had to be reported in numerical form.

There was an additional criterion for the inclusion of studies in our pooled analysis. A study was included if it was possible to abstract or calculate the mean and standard deviation of the change in outcomes for that study. A standard deviation of the change cannot be directly calculated from pre- and post-treatment means and standard deviations. If only one study is available at a given study duration, a mean difference (MD) and a 95\% confidence interval (CI) are reported. If more than one study is available, the studies are pooled into a weighted mean difference (WMD) and $95 \% \mathrm{CI}$.

\section{Risk of Bias within Studies}

Risk of bias within studies was evaluated according to the criteria outlined in the Cochrane Handbook for Systematic Reviews of Interventions. ${ }^{11}$ Each study was given a score of "High Quality," "Unclear," or "Low Quality" in response to the following 5 questions: 1) Is an appropriate method of sequence generation for randomization described? 2) Was group allocation concealed from the researcher until after randomization? 3) Assuming that the population could not be blinded to group in an exercise trial, were the statisticians and researchers measuring outcomes blinded? 4) Was outcome data reported for all patients or appropriate reasons 
given for those lost to follow-up? and 5) Were all outcomes described in the study protocol reported in the paper?

\section{Classification of Outcomes}

We examined the mean difference between the exercise and the control group for the change in each of the following physiological characteristics. Anthropometric outcomes included BMI, percent fat, total fat, total abdominal fat, subcutaneous abdominal fat, visceral abdominal fat, waist circumference, weight, and waist hip ratio. Cardiovascular risk outcomes included blood pressure (resting systolic and diastolic), maximum oxygen capacity, maximum oxygen capacity per kilogram, maximum heart rate, and resting heart rate. Lipid outcomes included high-density lipoprotein, lowdensity lipoprotein, total cholesterol, and triglyceride levels. Fasting glucose levels, fasting insulin levels, and safety outcomes also were extracted if available. For each outcome, the mean difference (MD), defined as the difference between the mean change in the exercise group and the mean change in the control group, is reported. Where possible, $95 \%$ CIs of the MD also are reported.

\section{Data Collection Process and Data Items}

For each included RCT, we extracted information using a standardized data extraction form. Extraction was performed in duplicate, and disagreements were resolved by consensus or, when necessary, by a third reviewer. We recorded data about the characteristics of cardiovascular health, exercise intervention, fasting glucose, insulin levels, lipid profiles, and patient characteristics. Lipid data was recorded in conventional units (milligrams/deciliter). When RCTs presented data for multiple follow-up visits, we extracted data from the longest period.

\section{Statistical Methods}

For our meta-analysis, we pooled treatment effects across RCTs of equivalent follow-up length. WMDs were calculated for several outcome measures in the exercise and the control groups. The DerSimonian and Laird ${ }^{12}$ random-effect model was employed as we anticipated heterogeneity between trials. We used Meta-Analyst ${ }^{13}$ and Stata $9.0^{14}$ software (StataCorp LP, College Station, Tex) for statistical analyses.

\section{RESULTS}

We identified 1847 potentially relevant studies in our literature search (Figure 1). We eliminated 1663 on the basis of their abstracts. The full texts were retrieved for 184 studies. An additional 11 studies were drawn from previous reviews and the bibliographies of included studies. After review of these full texts, 14 trials were identified that met the inclusion/ exclusion criteria of our systematic review. All trials with 6- or 12 -month exercise programs were included in the meta-analysis. The 8 trials with 12- to 16 -week interventions did not report a standard deviation for the change in each outcome. For this reason, these studies were not pooled.

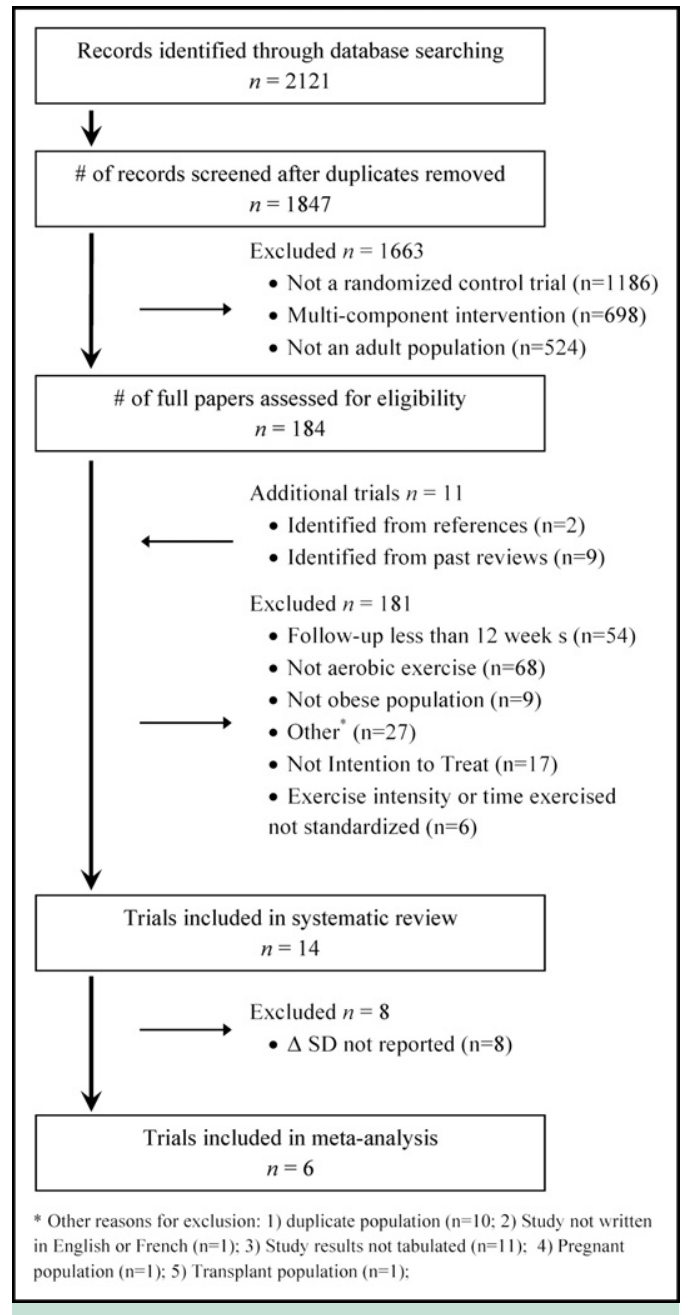

Figure 1 Flow diagram of trials included in the meta-analysis following the PRISMA statement on preferred reporting for meta-analyses. ${ }^{33} \Delta \mathrm{SD}=$ Change in standard deviation.

\section{Study and Patient Characteristics}

Included studies were classified into 3 groups according to the length of the exercise program: 2 studies (265 patients) had a 12-month exercise intervention, 4 studies (861 patients) had a 6-month intervention, and 8 studies (414 patients) had a 12-16-week intervention (Table 1). The age of the patient population varied between studies. Specifically, 4 studies had patient populations with a mean age $>60$ years and 1 study recruited only young patients aged between 19 and 23 years. ${ }^{15}$ With the exception of 2 Japanese studies ${ }^{15,16}$ and a Brazilian study, ${ }^{17}$ all studies were located in Europe or North America. Eight studies explicitly recruited sedentary individuals.

Eight studies allowed patients to choose from a range of exercise modalities. Walking, jogging, and cycle ergometers were the most common modalities. There also were instances of aerobics, mini-trampoline, and rowing ergometers. Weekly exercise programs ranged from 120 to 240 minutes per week. Exercise intensities ranged from $40 \%$ to 
Table 1 Study and Patient Characteristics of Randomized Control Trials Examining the Effect of Aerobic Exercise on Weight Loss, Blood Pressure, and Lipid Profiles

\begin{tabular}{|c|c|c|c|c|c|c|c|c|c|c|c|c|c|c|c|c|}
\hline \multirow[b]{2}{*}{ First Author, Year } & \multirow[b]{2}{*}{$\mathrm{n}$} & \multirow[b]{2}{*}{$\begin{array}{l}\text { Age, } \\
\text { Years }\end{array}$} & \multirow[b]{2}{*}{$\begin{array}{l}\% \\
\text { Male }\end{array}$} & \multirow[b]{2}{*}{ Location } & \multirow[b]{2}{*}{ Study Population } & \multicolumn{3}{|l|}{ Treatment Group } & \multirow{2}{*}{$\begin{array}{l}\text { Control } \\
\text { Group } \\
\text { Mode }\end{array}$} & \multicolumn{7}{|c|}{ Baseline Population Characteristics } \\
\hline & & & & & & $\begin{array}{l}\text { Exercise } \\
\text { Modality }\end{array}$ & $\begin{array}{l}\text { Weekly } \\
\text { Exercise } \\
\text { (min) }\end{array}$ & $\begin{array}{l}\text { Exercise } \\
\text { Intensity } \\
(\%)\end{array}$ & & BMI & $\begin{array}{l}\text { WT } \\
(\mathrm{kg})\end{array}$ & $\begin{array}{l}W C \\
(\mathrm{~cm})\end{array}$ & $\begin{array}{l}\text { SBP } \\
(\mathrm{mm} \mathrm{Hg})\end{array}$ & $\begin{array}{l}\text { DBP } \\
(\mathrm{mm} \mathrm{Hg})\end{array}$ & $\begin{array}{l}\mathrm{TC} \\
(\mathrm{mg} / \mathrm{dL})\end{array}$ & $\begin{array}{l}\mathrm{TG} \\
(\mathrm{mg} / \mathrm{dL})\end{array}$ \\
\hline \multicolumn{17}{|l|}{ 12-Month program } \\
\hline Irwin, $2003^{18}$ & 173 & 60.7 & 0 & USA & $\begin{array}{l}\text { Sedentary, nonsmokers, } \\
\text { postmenopausal }\end{array}$ & Walk, Cycle Erg & 225 & $60-75 \mathrm{HR}$ & Stretch & 31 & 82 & 93 & - & - & - & - \\
\hline $\begin{array}{l}\text { Anderssen, } \\
1995^{19}\end{array}$ & 92 & $41-50$ & 100 & Norway & Sedentary & Walk, Aerobics & 180 & $60-80 \mathrm{HR}$ & None & 28 & 90 & 102 & 130 & 88 & 250 & 197 \\
\hline \multicolumn{17}{|c|}{ 6-Month program } \\
\hline Nishijima, $2007^{16}$ & 561 & 67.0 & 44 & Japan & Hypertensive & Cycle Erg & 180 & $70 \mathrm{VO}_{2}$ & Attent. & 27 & 65 & 89 & 140 & 83 & 222 & 174 \\
\hline Alves, $2009^{17}$ & 156 & 39.4 & 100 & Brazil & Sedentary, low SE status & Walk, Aerobics & 150 & 40-60 HR & None & 30 & 73 & - & - & - & - & - \\
\hline $\begin{array}{l}\text { Blumenthal, } \\
2000^{26}\end{array}$ & 66 & 46.6 & 0 & USA & Sedentary, low BMD & $\begin{array}{l}\text { Cycle Erg, Walk, } \\
\text { Jog }\end{array}$ & 140 & 70-85 HR & None & 32.7 & 94.9 & - & 141 & 94 & - & - \\
\hline Hellenius, $2003^{27}$ & 78 & 46.0 & 100 & Sweden & $\begin{array}{l}\text { Heart disease } \\
\text { prevention program }\end{array}$ & Walk, Jog & 135 & $60-80 \mathrm{HR}$ & None & 25.0 & - & 92 & 132 & 82 & 233 & 125 \\
\hline \multicolumn{17}{|l|}{ 12-16-Week program } \\
\hline Posner, $1992^{28}$ & 247 & 68.6 & 38 & USA & Sedentary, elderly & Cycle Erg & 120 & $70 \mathrm{HR}$ & Attent. & - & 69.0 & - & 128 & 75 & - & - \\
\hline Bonanno, $1974^{29}$ & 39 & 41.3 & 100 & USA & Police, firemen & Jog, Walk & 165 & 70-85 HR & None & - & 89.8 & - & 143 & 95 & 264 & 231 \\
\hline Raz, $1994^{30}$ & 38 & 56.7 & 35 & Israel & Diabetic patients & $\begin{array}{l}\text { Cycle Erg, Row } \\
\text { Erg, Treadmill }\end{array}$ & 135 & $65 \mathrm{VO}_{2}$ & None & 31.0 & - & - & - & - & 228 & 182 \\
\hline Lambers, $2008^{20}$ & 29 & 52.2 & 76 & Holland & Diabetic patients & $\begin{array}{l}\text { Treadmill, Cycle } \\
\text { Erg }\end{array}$ & 180 & $60-85$ HR & None & 30.7 & 92.8 & 110 & - & - & 186 & 178 \\
\hline Abe, $1997^{15}$ & 17 & $19-23^{*}$ & 0 & Japan & Sedentary & Cycle & 120 & 50-60 HR & None & - & 53.5 & - & - & - & - & - \\
\hline DiPietro, $1998^{31}$ & 16 & 72 & 19 & USA & Elderly & Mini-trampoline & 240 & $75 \mathrm{HR}$ & Stretch & 27.2 & 66.8 & 95.0 & - & - & - & - \\
\hline $\begin{array}{l}\text { van Aggel- } \\
\text { Leijssen, } 2001^{32}\end{array}$ & 13 & 37.7 & 0 & Netherlands & $\begin{array}{l}\text { Sedentary, } \\
\text { premenopausal }\end{array}$ & Cycle Erg & 180 & $40 \mathrm{VO}_{2}$ & None & 32.7 & 90.3 & - & - & - & - & - \\
\hline $\begin{array}{l}\text { van Aggel- } \\
\text { Leijssen, } 2001^{32}\end{array}$ & 15 & 42.7 & 100 & Netherlands & Sedentary & Cycle Erg & 180 & $40 \mathrm{VO}_{2}$ & None & 31.9 & 101 & - & - & - & - & - \\
\hline \multicolumn{17}{|c|}{ 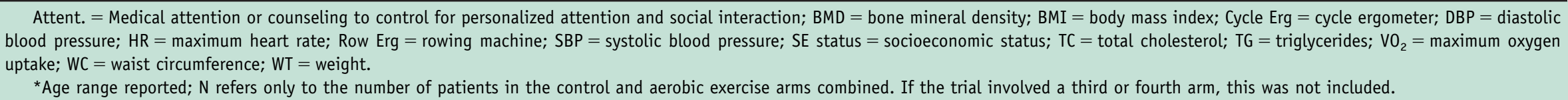 } \\
\hline
\end{tabular}


$85 \%$ maximum heart rate and from $40 \%$ to $70 \%$ maximum oxygen uptake. The control groups were either instructed to continue their current lifestyle habits $(\mathrm{n}=10)$, participate in a regular stretching group $(n=2)$, or participate in a medical attention program $(\mathrm{n}=2)$.

Four study populations were overweight and 7 populations were obese (Table 1). The remaining 3 studies did not report baseline BMI or height, but limited inclusion to overweight or obese patients. Baseline mean weight varied from $53.5 \mathrm{~kg}$ (a female Japanese population) to $94.9 \mathrm{~kg}$. Only 6 studies reported baseline waist circumference, 3 of which reported populations with abdominal obesity (waist $\geq 102 \mathrm{~cm}$ in men and $\geq 88 \mathrm{~cm}$ in women). ${ }^{18-20}$ All 6 study populations reporting baseline systolic and diastolic blood pressure were prehypertensive or Stage 1 hypertensive according the American Heart Association definition. ${ }^{21}$ Five of 6 study populations had high total cholesterol, and 1 study population had high triglyceride levels at baseline.

\section{Risk of Bias}

There was some risk of bias within individual studies (Figure 2). Only 1 study explicitly described how it generated its randomization sequence. Three of the 14 studies did not conceal allocation until after randomization. Four studies explicitly reported blinding either their outcome measurement team or statistician. No study had missing outcome data because this was an exclusion criterion (intention to treat only). However, 7 studies did not explicitly describe the reasons that patients were lost to follow-up. One study selectively reported outcomes; however, these outcomes were not among those reported in our review.

\section{Systematic Review of Outcomes}

Results are reported as mean differences (MD), defined as the difference between the mean change in the exercise group and the mean change in the control group. For all outcomes reported in this review, a negative mean difference favors exercise. Eleven studies reported mean change

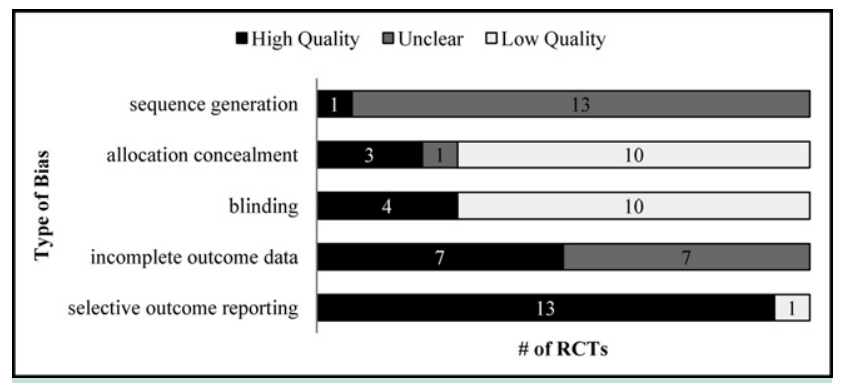

Figure 2 Risk of Bias within Studies: This tool is from the Cochrane Clinical Trial Handbook. ${ }^{11}$ Each study is given a score of "High Quality," "Low Quality," or "Unclear" for 5 questions. These questions evaluate the randomization process and outcome reporting of the trials. The number of studies receiving a given score is superimposed on the bar graph. $\mathrm{RCT}=$ randomized controlled trial. in weight over the intervention period (Table 2). For trials with a $12-16$-week exercise program $(n=6)$, mean differences ranged from $0.8 \mathrm{~kg}$ to $-2.5 \mathrm{~kg}$. The exercise group was favored in all 6-month exercise programs $(\mathrm{n}=3,-1.6$ to $-2.5 \mathrm{~kg})$ and all 12 -month exercise programs $(\mathrm{n}=2$, -1.4 to $-2.0 \mathrm{~kg}$ ). Six studies reported mean change in waist circumference (Table 2). Mean differences in waist circumference in 3-month interventions $(n=2)$ ranged from 0.9 to $-0.5 \mathrm{~cm}$. Exercise favored modest waist circumference reduction in all 6-month $(\mathrm{n}=2,-2.1$ to -4.0 $\mathrm{cm})$ and 12-month interventions ( $\mathrm{n}=2,-1.1$ to $-2.8 \mathrm{~cm}$ ).

All 5 studies that reported MDs for systolic and diastolic blood pressure showed modest reductions that favored exercise. Only 4 of 6 studies that reported change in total cholesterol favored exercise. The 5 studies reporting on triglyceride levels favored exercise (Table 2).

\section{Pooled Analysis}

Six-month aerobic exercise programs were associated with a modest decrease in weight (WMD $=-1.6 \mathrm{~kg}$ ), as were 12month programs (WMD $=-1.7 \mathrm{~kg}$ ) (see Figure 3 for CIs). Six-month programs $(\mathrm{WMD}=-2.12 \mathrm{~cm})$ and 12 -month programs $(\mathrm{WMD}=-1.95 \mathrm{~cm}$ ) were also associated with modest reductions in waist circumference (see Figure 4 for CIs). At 6 months, aerobic exercise resulted in small reductions for systolic blood pressure (Figure 5), diastolic blood pressure (WMD $=-1.8 \mathrm{~mm} \mathrm{Hg} ; 95 \% \mathrm{CI},-3.43$ to -0.16 ) and total cholesterol (WMD $=-1.54 \mathrm{mg} / \mathrm{dL} ; 95 \% \mathrm{CI},-3.39$ to 0.30 ). There were an insufficient number of studies reporting these outcomes at 12 months to carry out a pooled analysis.

\section{DISCUSSION}

Our study was designed to determine the efficacy of isolated aerobic exercise programs at reducing weight and cardiovascular risk in overweight and obese populations. We found that aerobic exercise programs of moderate intensity, with durations ranging from 12 weeks to 12 months, resulted in modest weight and waist circumference reduction. This result suggests that a program of isolated aerobic exercise is not an efficacious weight loss therapy for overweight and obese populations. Isolated aerobic exercise does provide modest improvements in systolic blood pressure, diastolic blood pressure, total cholesterol, and triglyceride levels, and it may still work synergistically, in conjunction with diet, as a weight loss therapy.

Previous systematic reviews suggest a linear dose-response relationship between aerobic exercise and weight loss, but only for interventions $<16$ weeks in duration with a controlled diet. This relationship has not been shown for longer interventions. ${ }^{6}$ A Cochrane review reported a weight reduction effect size of $-2.03 \mathrm{~kg}$ for exercise versus no treatment. The review also reported that exercise is associated with a small decrease in SBP and DBP. ${ }^{22}$ A metaanalysis of 68 RCTs with 2674 overweight subjects concluded that the BP-lowering effect of activity is modest in normotensive patients and more pronounced in hypertensive 
Table 2 Change in Weight, Waist Circumference, Blood Pressure, and Lipid Profiles

\begin{tabular}{|c|c|c|c|c|c|c|c|}
\hline & First Author, Year & $\begin{array}{l}\text { Exercise } \\
n\end{array}$ & $\begin{array}{l}\text { Control } \\
n\end{array}$ & Exercise & & Control & \\
\hline \multicolumn{4}{|l|}{ Weight } & \multicolumn{4}{|c|}{$\Delta$ Weight $(\mathrm{kg}) \pm \mathrm{SD}^{*}$} \\
\hline & Anderssen, $1995^{19}$ & 49 & 43 & -0.9 & $(0.6)$ & 1.1 & $(0.4)$ \\
\hline \multirow[t]{2}{*}{ 6-Month program } & Nishijima, $2007^{16}$ & 281 & 280 & -1.9 & $(0.3)$ & -0.3 & $(0.2)$ \\
\hline & Alves, $2009^{17}$ & 78 & 78 & -1.3 & $(2.4)$ & 0.4 & $(2.4)$ \\
\hline & Lambers, $2000^{20}$ & 18 & 11 & -0.6 & - & -0.3 & - \\
\hline & Abe, $1997^{15}$ & 9 & 8 & -3.1 & - & -0.6 & - \\
\hline & DiPietro, $1998^{31}$ & 9 & 7 & -1.0 & - & 0.0 & - \\
\hline & Van Aggel, $2001^{32}$ & 7 & 6 & 0.6 & - & -0.2 & - \\
\hline & Van Aggel, $2001^{32}$ & 7 & 8 & -1.1 & - & -0.6 & - \\
\hline & Hellenius, $2003^{27}$ & 39 & 39 & -2.2 & $(1.0)$ & 0.3 & $(0.8)$ \\
\hline \multirow[t]{2}{*}{ 12-16-Week program } & Lambers, $2000^{20}$ & 18 & 11 & -1.3 & - & -0.8 & - \\
\hline & DiPietro, $1998^{31}$ & 9 & 7 & -2.2 & - & -3.1 & - \\
\hline \multicolumn{4}{|l|}{ Systolic blood pressure } & \multicolumn{4}{|c|}{$\Delta \mathrm{SBP}(\mathrm{mm} \mathrm{Hg}) \pm \mathrm{SD}$} \\
\hline 12-Month program & Anderssen, $1995^{19}$ & 49 & 43 & -2.2 & $(1.1)$ & -0.5 & $(1.7)$ \\
\hline \multirow[t]{2}{*}{ 6-Month program } & Nishijima, $2007^{16}$ & 281 & 280 & -8.3 & $(1.7)$ & -6.2 & $(1.4)$ \\
\hline & Hellenius, $2003^{27}$ & 39 & 39 & -5.0 & $(4.0)$ & -1.0 & $(2.0)$ \\
\hline \multirow[t]{2}{*}{ 12-16-Week program } & Posner, $1992^{28}$ & 166 & 81 & -3.3 & - & 2.3 & - \\
\hline & Lambers, $2000^{20}$ & 18 & 11 & -6.6 & - & -3.0 & - \\
\hline \multicolumn{4}{|l|}{ Diastolic blood pressure } & \multicolumn{4}{|c|}{$\Delta \mathrm{DBP}(\mathrm{mm} \mathrm{Hg}) \pm \mathrm{SD}$} \\
\hline 12-Month program & Anderssen, $1995^{19}$ & 49 & 43 & -2.7 & $(1.0)$ & -0.7 & $(1.3)$ \\
\hline & Hellenius, $2003^{27}$ & 39 & 39 & -4.7 & $(9.0)$ & -5.1 & $(7.8)$ \\
\hline \multirow[t]{3}{*}{ 12-16-Week program } & Bonanno, $1974^{29}$ & 20 & 19 & -12.0 & - & 6.0 & - \\
\hline & Raz, $1994^{30}$ & 19 & 19 & -3.9 & - & 0.0 & - \\
\hline & Lambers, $2000^{20}$ & 18 & 11 & 0.3 & - & 0.0 & - \\
\hline \multicolumn{4}{|l|}{ Triglycerides } & \multicolumn{4}{|c|}{$\Delta \mathrm{TG}(\mathrm{mg} / \mathrm{dL}) \pm \mathrm{SD}$} \\
\hline 12-Month program & Anderssen, $1995^{19}$ & 49 & 43 & -21.4 & $(8.9)$ & 15.1 & $(12.5)$ \\
\hline 6-Month program & Hellenius, $2003^{27}$ & 39 & 39 & -8.9 & $(21.4)$ & 5.3 & (12.5) \\
\hline \multirow[t]{3}{*}{ 12-16-Week program } & Bonanno, $1974^{29}$ & 20 & 19 & -10.0 & - & 9.0 & - \\
\hline & Raz, $1994^{30}$ & 19 & 19 & -8.9 & - & 8.9 & - \\
\hline & Lambers, $2000^{20}$ & 18 & 11 & -17.8 & - & -8.9 & - \\
\hline
\end{tabular}

$\mathrm{DBP}=$ diastolic blood pressure; $\mathrm{SBP}=$ systolic blood pressure; $\mathrm{SD}=$ standard deviation; $\mathrm{TC}=$ total cholesterol; $\mathrm{TG}=$ triglycerides; $\mathrm{WC}=$ waist circumference.

* Means of change could be calculated from studies that only reported pre-treatment and post-treatment values. Standard deviations could not be calculated and are therefore not reported in this table.

patients. The weighted net reduction of blood pressure in response to dynamic physical training averaged $-3.4 \mathrm{~mm}$ $\mathrm{Hg}$ for SBP and $-2.4 \mathrm{~mm} \mathrm{Hg}$ for DBP, and appeared to be unrelated to the initial body BMI. ${ }^{23}$ These reviews also suggest a favorable effect on cholesterol and a reduction in triglycerides but present no RCT evidence. ${ }^{6}$
There are several possible explanations for the inefficacy of isolated aerobic exercise programs for weight loss. First, these programs may be hindered by nonadherence to the exercise protocol. Only intention-to-treat trials were included in our study, which would capture the mitigating effect of this nonadherence. Nonadherence is thought to be 


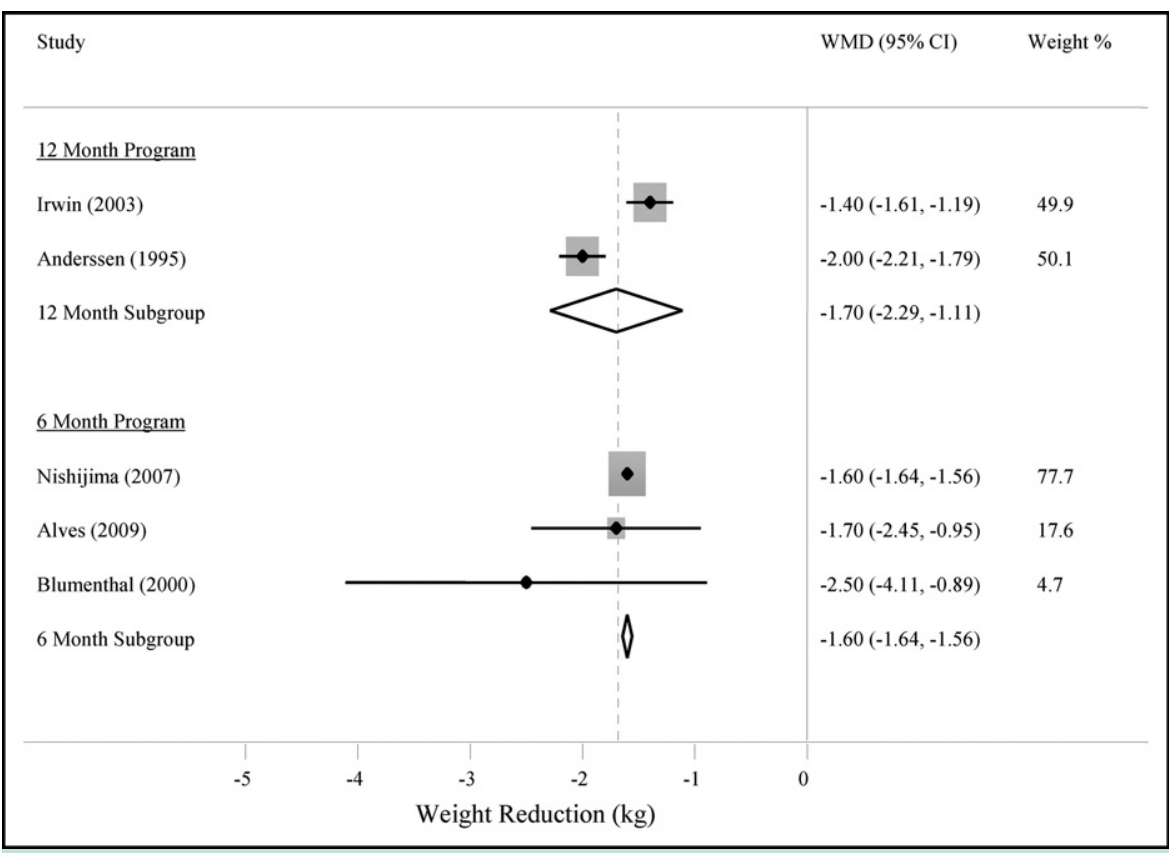

Figure 3 Meta-analysis of the impact of aerobic exercise programs on weight $(\mathrm{kg})$. The mean difference (MD) for each study reporting change in weight is depicted along with the $95 \%$ confidence interval. When more than 1 study is available at a given follow-up length, a weighted mean difference (WMD) is calculated. Weights are derived from a randomeffect analysis. A negative value is said to favor exercise because the exercise group experienced more weight reduction than the control.

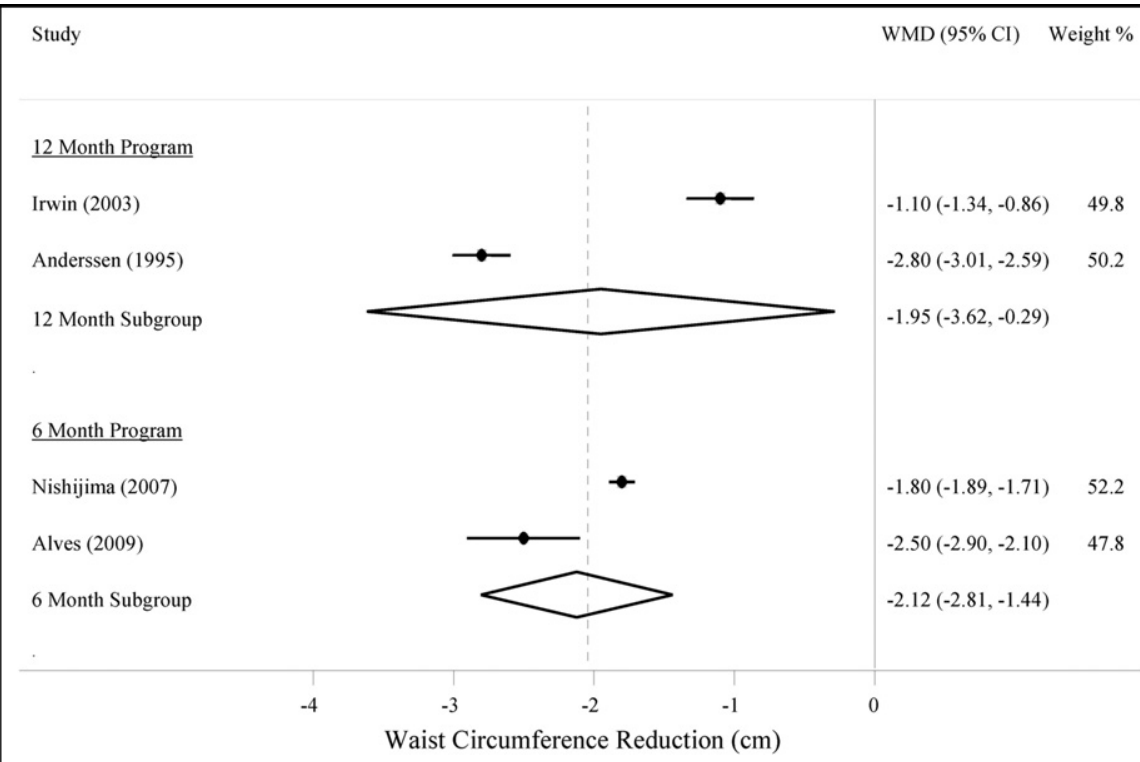

Figure 4 Meta-analysis of the impact of aerobic exercise on waist circumference $(\mathrm{cm})$. The mean difference (MD) for each study reporting change in waist circumference is depicted along with the $95 \%$ confidence interval. When more than one study is available at a given follow-up length, a weighted mean difference (WMD) is calculated. Weights are derived from a random-effect analysis. A negative value is said to favor exercise because the exercise group experienced more waist circumference reduction than the control. 


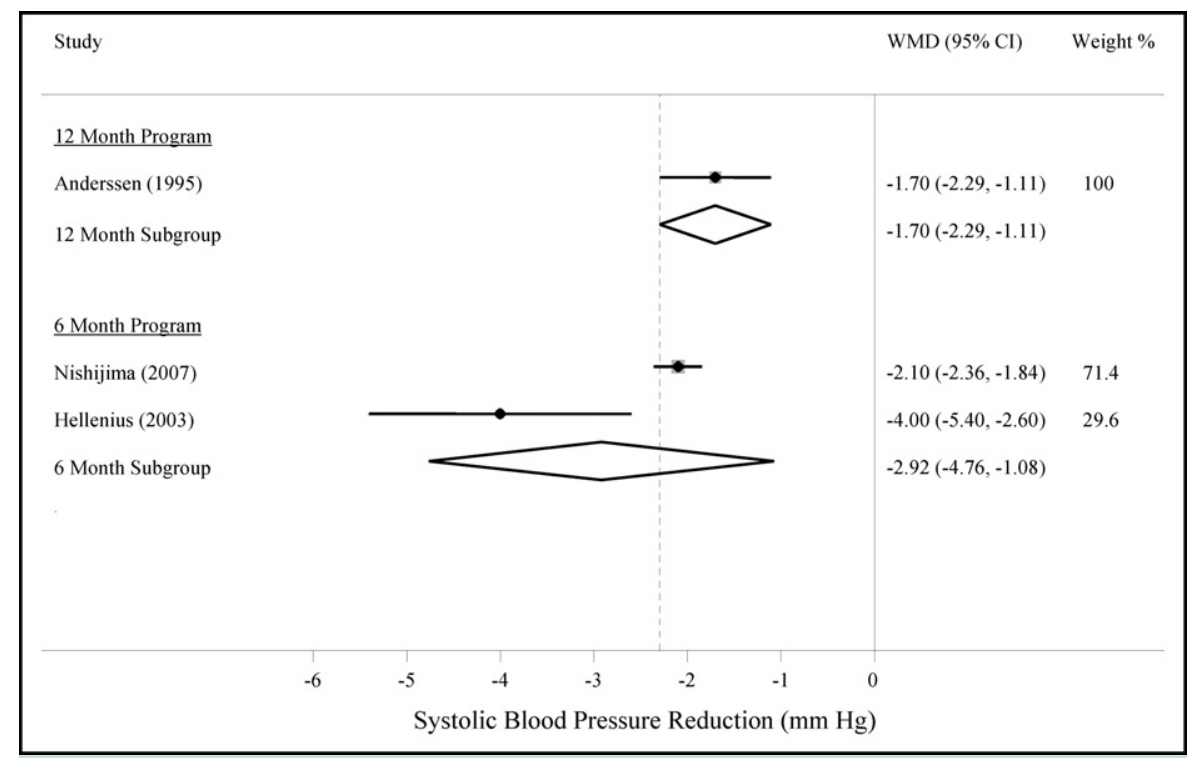

Figure 5 Meta-analysis of the impact of aerobic exercise on systolic blood pressure (mm $\mathrm{Hg}$ ). The mean difference (MD) for each study reporting change in systolic blood pressure is depicted along with the $95 \%$ confidence interval. When more than one study is available at a given follow-up length, a weighted mean difference (WMD) is calculated. Weights are derived from a random-effect analysis. A negative value is said to favor exercise because the exercise group experienced more blood pressure reduction than the control.

a particular issue for long-term programs. ${ }^{24}$ Second, an increase in caloric intake may offset the benefits of an aerobic exercise program. For this reason, our review does not rule out the synergistic effects of aerobic exercise when combined with diet. ${ }^{22}$ Third, aerobic exercise may be underprescribed in the trials included in this review. Moderate aerobic exercise of 225 minutes has been suggested as a guideline for weight loss programs. ${ }^{24}$ Only 2 of the studies in our review met this condition. Higher exercise intensity also may increase the efficacy of aerobic exercise in obese and overweight populations. ${ }^{22}$

Large cross-sectional studies have demonstrated reduction in blood pressure in regular exercisers irrespective of weight. ${ }^{25}$ The modest decrease presented in our review may be due to the fact that many of the patients in the study were predominantly normotensive or prehypertensive. A large decrease would not be expected for these populations. Aerobic exercise may still improve plasma lipoprotein status by increasing the proportion of high-density lipoproteins, despite our demonstration that it does not lead to a large reduction in total cholesterol. ${ }^{22}$

Our study has several potential limitations. First, publication bias may have affected our estimation of aerobic exercise. This is a limitation that affects virtually all meta-analyses. Second, the validity of our pooled estimates was limited by the inherent assumptions of meta-analysis. These estimates were synthesized from the limited data reported in published articles. A third limitation of this meta-analysis was the heterogeneity between included studies. Study populations differed in several respects (age, country of recruitment, smoking status, sex) as well as exercise interventions (exercise modality, intensity of exercise, level of supervision and time exercised per week). We attempted to limit this heterogeneity by using strict inclusion and exclusion criteria. Finally, there were studies that did not report a measure of variance of the change in mean for outcomes. We also were without access to patient-level data, so we could not calculate a measure of variance directly. These studies were not included in our pooled analysis, but they were tabulated as part of our systematic review.

\section{CONCLUSION}

An isolated, moderate-intensity aerobic exercise program is an ineffective weight loss intervention for overweight and obese populations. Aerobic exercise programs of 12 weeks to 12 months in length resulted in modest weight and waist circumference reduction. Aerobic exercise does provide modest improvements in cardiovascular risk and lipid levels and may have value as part of a combination program with diets. Patients and health care workers, however, should be aware that its value as an independent weight loss intervention for overweight and obese populations is limited.

\section{ACKNOWLEDGMENT}

We would like to thank Tara Dourian for her help with data extraction.

\section{References}

1. Benjamin R. The Surgeon General's Vision for a Healthy and Fit Nation. Rockville, MD: U.S. Department of Health and Human Services, Public Health Service, Office of the Surgeon General; 2010.

2. Flegal KM, Carroll MD, Ogden CL, Curtin LR. Prevalence and trends in obesity among US adults, 1999-2008. JAMA. 2010;303(3):235-241. 
3. Canadian Fitness and Lifestyle Research Institute. 2007 Physical Activity Monitor. Ottawa, ON: Canadian Fitness and Lifestyle Research Institute; 2007

4. Luo W, Morrison H, de Groh M, et al. The burden of adult obesity in Canada. Chronic Dis Can. 2007;27(4):135-144.

5. Grundy S, Blackburn G, Higgins M, Lauer R, Perri M, Ryan D. Physical activity in the prevention and treatment of obesity and its comorbidities. Med Sci Sports Exerc. 1999;31(11):S502-S508.

6. Haennel R, Lemire F. Physical activity to prevent cardiovascular disease. How much is enough? Can Fam Physician. 2002;48(1):65-71.

7. Ross R, Janssen I. Is abdominal fat preferentially reduced in response to exercise-induced weight loss? Med Sci Sports Exerc. 1999;31(11): S568-S572.

8. Ross R, Janssen I. Physical activity, total and regional obesity: dose-response considerations. Med Sci Sports Exerc. 2001;33(6 Suppl):S521-S527.

9. Kay S, Singh M. The influence of physical activity on abdominal fat: a systematic review of the literature. Obes Rev. 2006;7(2):183-200.

10. Ohkawara K, Tanaka S, Miyachi M, Ishikawa-Takata K, Tabata I. A dose-response relation between aerobic exercise and visceral fat reduction: systematic review of clinical trials. Int J Obes. 2007;31(12): 1786-1797.

11. Higgins JPT, Altman DG, eds. Chapter 8: Assessing risk of bias in included studies. In: Higgins J, Green S, eds. Cochrane Handbook for Systematic Reviews of Interventions, Version 5.0.1 [updated September 2008]. Oxford, UK: The Cochrane Collaboration; 2008.

12. DerSimonian R, Laird N. Meta-analysis in clinical trials. Control Clin Trials. 1986;7(3):177-188.

13. Wallace BC, Schmid CH, Lau J, Trikalinos TA. Meta-Analyst: software for meta-analysis of binary, continuous and diagnostic data. $B M C$ Med Res Methodol. 2009;9:80.

14. Stata Statistical Software: Release 9 [computer program]. College Station, TX: StataCorp LP; 2005.

15. Abe T, Kawakami Y, Sugita M, Fukunaga T. Relationship between training frequency and subcutaneous and visceral fat in women. Med Sci Sports Exerc. 1997;29(12):1549-1553.

16. Nishijima H, Satake K, Igarashi K, Morita N, Kanazawa N, Okita K. Effects of exercise in overweight Japanese with multiple cardiovascular risk factors. Med Sci Sports Exerc. 2007;39(6):926-933.

17. Alves JG, Gale CR, Mutrie N, Correia JB, Batty GD. A 6-month exercise intervention among inactive and overweight favela-residing women in Brazil: the Caranguejo Exercise Trial. Am J Public Health. 2009;99(1):76-80.

18. Irwin ML, Yasui Y, Ulrich CM, et al. Effect of exercise on total and intra-abdominal body fat in postmenopausal women: a randomized controlled trial. JAMA. 2003;289(3):323-330.

19. Anderssen S, Haaland A, Hjermann I, Urdal P, Gjesdal K, Holme I. Oslo Diet Exercise Study: a one-year randomized intervention trial. Effect on hemostatic variables and other coronary risk factors. Nutr Metab Cardiovasc Dis. 1995;5:189-236.

20. Lambers S, Van Laethem C, Van Acker K, Calders P. Influence of combined exercise training on indices of obesity, diabetes and cardiovascular risk in type 2 diabetes patients. Clin Rehabil. 2008;22(6):483-492.

21. Chobanian A, Bakris G, Black H, et al. Seventh report of the joint national committee on prevention, detection, evaluation, and treatment of high blood pressure. Hypertension. 2003;42(6):1206-1252.

22. Shaw K, Gennat H, O'Rourke P, Del Mar C. Exercise for overweight or obesity. Cochrane Database Syst Rev. 2006(4):CD003817.

23. Fagard R. Physical activity in the prevention and treatment of hypertension in the obese. Med Sci Sports Exerc. 1999;31(11 Suppl):S624-S630.

24. Donnelly JE, Hill JO, Jacobsen DJ, et al. Effects of a 16-month randomized controlled exercise trial on body weight and composition in young, overweight men and women: the Midwest Exercise Trial. Arch Intern Med. 2003;163(11):1343-1350.
25. Montoye HJ, Metzner HL, Keller JB, Johnson BC, Epstein FH. Habitual physical activity and blood pressure. Med Sci Sports. 1972;4(4):175-181.

26. Blumenthal J, Sherwood A, Gullette E, et al. Exercise and weight loss reduce blood pressure in men and women with mild hypertension: effects on cardiovascular, metabolic, and hemodynamic functioning. Arch Intern Med. 2000;160(13):1947.

27. Hellenius M, De Faire U, Berglund B, Hamsten A, Krakau I. Diet and exercise are equally effective in reducing risk for cardiovascular disease. Results of a randomized controlled study in men with slightly to moderately raised cardiovascular risk factors. Atherosclerosis. 1993;103(1):81-91.

28. Posner J, Gorman K, Windsor-Landsberg L, et al. Low to moderate intensity endurance training in healthy older adults: physiological responses after four months. J Am Geriatr Soc. 1992;40(1):1.

29. Bonanno JA, Lies JE. Effects of physical training on coronary risk factors. Am J Cardiol. 1974;33(6):760-764

30. Raz I, Hauser E, Bursztyn M. Moderate exercise improves glucose metabolism in uncontrolled elderly patients with non-insulin-dependent diabetes mellitus. Isr J Med Sci. 1994;30(10):766-770.

31. DiPietro L, Seeman T, Stachenfeld N, Katz L, Nadel E. Moderateintensity aerobic training improves glucose tolerance in aging independent of abdominal adiposity. J Am Geriatr Soc. 1998;46(7):875.

32. van Aggel-Leijssen DP, Saris WH, Homan M. van Baak MA. The effect of exercise training on beta-adrenergic stimulation of fat metabolism in obese men. Int J Obes Relat Metab Disord. 2001;25(1):16-23.

33. Moher D, Liberati A, Tetzlaff J, Altman D. Reprint-Preferred Reporting Items for Systematic Reviews and Meta-Analyses: the PRISMA Statement. Phys Ther. 2009;89(9):873.

\section{APPENDIX}

Search Strategy (for PubMed) - Jan 20, 2010:

("HDL"[tiab] OR "LDL"[tiab] OR "insulin"[tiab] OR "insulin" [MeSH terms] OR lipoprotei*[tiab] OR cholesterol[tiab] OR "blood pressure"[tiab] OR hypertension[tiab] OR "Triglycerides" [MeSH terms] OR "Cholesterol”"[MeSH terms] OR "Lipoproteins"[MeSH terms] OR "Blood Pressure" [MeSH terms] OR "Hypertension" [MeSH terms] OR "Blood Glucose"[MeSH terms] OR "BMI"[tiab] OR "body mass index"[tiab] OR "body weight"[tiab] OR "waist circumference"[tiab] OR "Waist Circumference"[MeSH terms] OR "Body Weight" [MeSH terms] OR "Body Mass Index"[MeSH terms] OR "Weight Loss" [MeSH terms] OR "weight loss"[tiab] OR "lose weight"[tiab]) AND (Overweight[MeSH terms] OR overweight[tiab] OR obes*[tiab] OR Obesity[MeSH] OR "Obesity, Morbid" [MeSH]) AND ("Exercise Therapy"[MeSH terms] OR Exercise[MeSH terms] OR "Physical Fitness"[MeSH terms] OR "Physical Exertion" [MeSH terms] OR exercis*[tiab] OR "physical fitness"[tiab] OR "physical exertion"[tiab] OR "physical activity"[tiab] OR "physical activities" [tiab] OR "physical training"[tiab] OR workout[tiab] OR "Resistance Training" [MeSH terms] OR "resistance training" [tiab]) NOT (cancer[tiab] OR neoplasm[tiab] OR Cancer[MeSH] OR Neoplasm[MeSH])

Limits: Clinical Trial, Randomized Control Trial, Controlled Clinical Trial, Humans, MEDLINE, English and French 